\title{
Annals of Pediatric Endocrinology \& Metabolism is now indexed in the Emerging Sources Citation Index
}

\author{
Ji-Eun Lee, MD, PhD \\ E-mail: anicca@inha.ac.kr \\ https://orcid.org/0000-0002-7386- \\ 0015
}

\section{Editor-in-Chief}

Department of Pediatrics, Inha university Hospital, Inha University College of Medicine, Incheon, Korea
On behalf of the our editorial board members, I am very happy to announce that Annals of Pediatric Endocrinology \& Metabolism (APEM) has been selected for coverage in Clarivate Analytics as Emerging Sources Citation Index (ESCI). This selection could provide a promising step for APEM to become an influential international journal. Thanks to dedication of the former editorial boards, APEM has been indexed in PubMed Central (PMC) since 2014, Embase since 2017, Scopus and Directory of Open Access Journals (DOAJ) since 2018.

The APEM is the official journal of the Korean Society of Pediatric Endocrinology. It is a peer-reviewed open access journal of medicine published in English. The journal was launched in 1996 under the title of 'Journal of Korean Society of Pediatric Endocrinology' until 2011 (pISSN 1226-2242). Since 2012, the title is changed to 'Annals of Pediatric Endocrinology \& Metabolism.' The Journal is published quarterly on the official APEM website (http://e-apem.org) to be distributed to institutions all over the world. It is now indexed in PubMed, PMC, Scopus, ESCI, KoreaMed, the Korean Medical Citation Index, Korea Citation Index, ScienceCentral, EBSCO, Embase, DOI/Crossref, DOAJ, Google Scholar.

I would like to express my sincere gratitude to all the editorial boards of APEM, all members of the Korean Society of Pediatric Endocrinology, and all international contributors. The achievement indexed in ESCI was possible with your enthusiasm and contribution. 